\title{
The necessity of an observational study on the interactions between allergic history and citrus fruit intake for the prevention of pancreatic cancer
}

\author{
Jong-Myon Bae \\ Department of Preventive Medicine, Jeju National University School of Medicine, Jeju, Korea
}

\begin{abstract}
While the main product of Jeju Island is citrus fruit and the prevalence of atopic dermatitis among the students who live there is relatively high, the incidence of pancreatic cancer is lowest in Korea. Systematic reviews reporting allergic history and intake of citrus fruit as protective factors against pancreatic cancer (PCC) were published in 2005 and 2008, respectively. Although there were discrepancies in the results of the subgroup analyses between case-control and cohort studies, it is necessary to evaluate an interaction effect between allergic history and intake of citrus fruits on PCC risk.
\end{abstract}

KEY WORDS: Pancreatic neoplasms, Risk factors, Allergy and immunology, Citrus, Meta-analysis

\section{INTRODUCTION}

Pancreatic cancer is a primary site cancer that has the 4th highest cancer mortality in North America [1] and a representative malignant tumor with a less than $5 \%$ chance of having a 5 -year survival rate [2]. Pancreatic cancer mortality was 5.6 per 100,000 among Korean populations in 2011, which was the 4th highest cancer mortality after lung cancer, liver cancer, and stomach cancer. It is the only primary site cancer to have shown no improvement in 5 -year survival rate over the past 10 years [3]. Therefore, an analytical epidemiology study is desperately needed to reveal the factors responsible for either the increase or decrease in pancreatic cancer risk [4]. Known modifiable risk factors include smoking, diet, and medical history [5], among which the most significant factors, according to systematic reviews (SRs) were allergic history [6] and citrus fruit intake [7].

Correspondence: Jong-Myon Bae

Department of Preventive Medicine, Jeju National University School of

Medicine, 102 Jejudaehak-ro, Jeju 690-756, Korea

Tel: +82-64-755-5567, Fax: +82-64-725-2593, E-mail: jmbae@jejunu.ac.kr

Received: May 16, 2015, Accepted: Jun 15, 2015, Published: Jun 16, 2015

This article is available from: http://e-epih.org/

(C) 2015, Korean Society of Epidemiology

(C) This is an open-access article distributed under the terms of the Creative Commons Attribution License (http://creativecommons.org/licenses/by/3.0/), which permits unrestricted use, distribution, and reproduction in any medium, provided the original work is properly cited.
On the other hand, pancreatic cancer incidence in Jeju Island, which is localized in the lowest latitude among the Korean local governments, is markedly lower than that of other local governments [8]. By the way, Jeju Island is the main area of citrus fruit production, and it is the area with the highest atopic dermatitis prevalence among elementary, middle, and high school students [9]. Considering these health-environmental facts, the present study was performed to investigate if it was possible to propose a hypothesis that the interactions between citrus fruit intake and allergic history would lower pancreatic cancer incidence.

\section{BODY}

Inhibitory effects of allergic history

In the SR on the effects of allergic history on pancreatic cancer published by Gandini et al. [6] in 2005, the meta-analysis of 10 case-control studies (CCS) and 4 cohort studies (COS) resulted in the inhibition of pancreatic cancer incidence with 0.82 in total summary relative risk (sRR) and 0.68 to 0.99 in $95 \%$ confidence intervals (CIs). However, none of the $4 \mathrm{COS}$ results were statistically significant [10-13].

Related citation lists for each of the 4 COSs were made using the "related citations" function provided by PubMed (National Library of Medicine, US), followed by manual searches [14,15], which led to additional discoveries of two COS articles published 


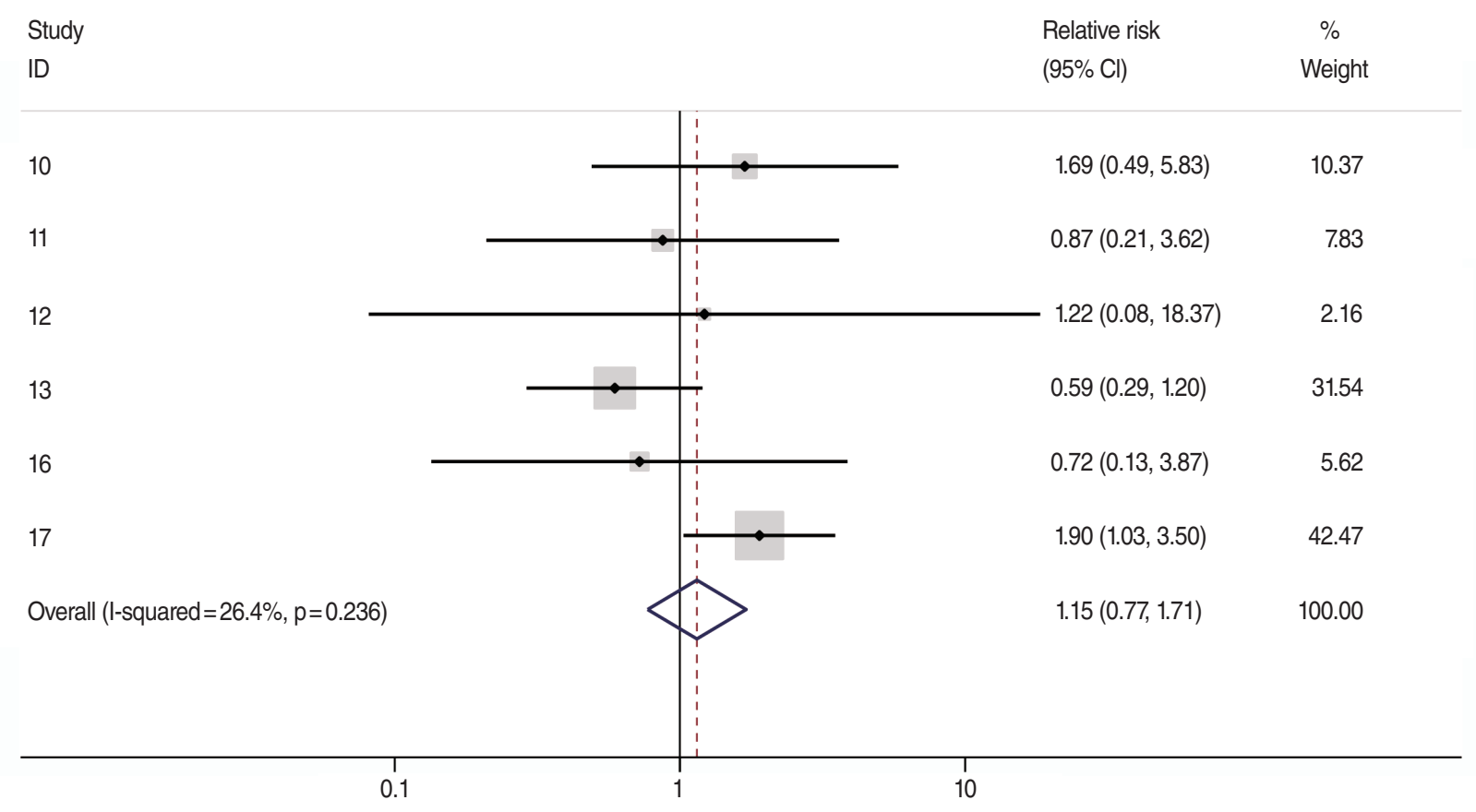

Figure 1. The forest plot of using a fixed-effects summary estimates in 6 cohort articles evaluating association between allergic history and pancreatic cancer risk. ID, reference number; $\mathrm{Cl}$, confidence interval.

in 2005 [16,17]. Nevertheless, there have been no COSs among articles published after 2006. Figure 1 is a forest plot that was obtained through meta-analysis using logarithmic relative risks $(\operatorname{logRR})$ of a total of 6 target articles and their standard errors (SElogRR). The sRR value applied to the fixed effects model at $26.4 \%$ of the I-square [18] value representing degree of heterogeneity was 1.15 (95\% CI, 0.77 to 1.71), which was not statistically significant. Begg's test resulted in a p-value of 0.71 , indicating no effect by a small-scale study, and there was no asymmetry effect on the corresponding funnel plot (Figure 2).

\section{Inhibitory effects of citrus fruit intake}

In the SR on the effect of citrus fruit intake on pancreatic cancer performed by Bae et al. in 2009 [7], the meta-analysis with 4 CCSs and 5 COSs found inhibition effects of pancreatic cancer incidence (sRR, 0.83 ; 95\% CI, 0.70 to 0.98 ). However, a subgroup analysis on the results of 5 COSs resulted in a sRR of 0.97 ( $95 \%$ CI, 0.86 to 1.10 ), which was not statistically significant. Related citation lists for each of the 5 COSs [19-23] were made using the "related citations" function in PubMed, followed by manual searches [14,15], which led to the finding of 6 additional COS articles [24-29]. By the way, it was found that the same cohort was used in the articles by Stolzenberg-Solomon et al. [20] and Bobe et al. [24], so Bobe et al.'s 2008 article [24] was selected for an analysis. In addition, since the cohorts described in the articles by Shigihara et al. [28] and Li et al. [29] were also the same, so Shigihara et al.'s 2014 article [28] was selected. More-

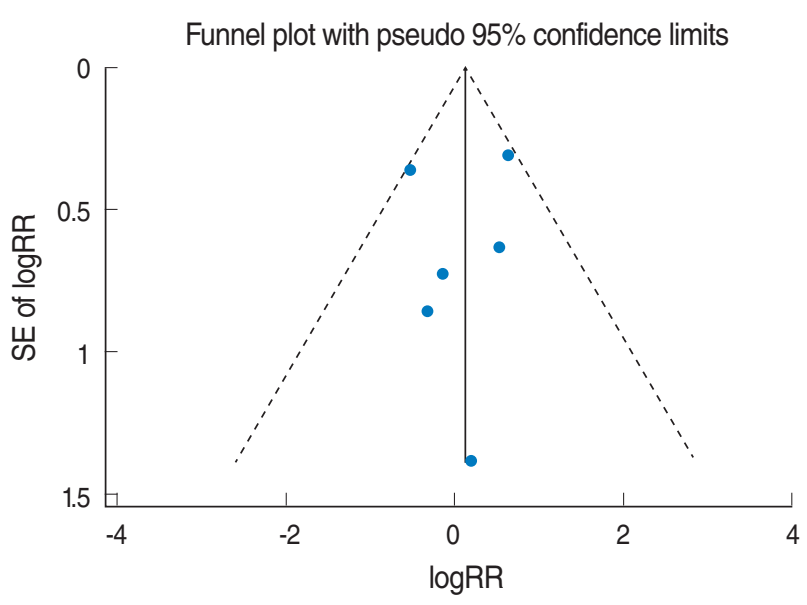

Figure 2. A funnel plot using fixed-effects summary estimates in 6 cohort articles evaluating the association between allergic history and pancreatic cancer risk. $\log R R$, log relative risk; SE of logRR, standard error of log relative risk.

over, the article by Coughlin et al. [19] concerning cancer mortality was excluded. Therefore, a total of 8 articles [21-28] were used for the meta-analysis.

Of these 8, sRR obtained from the meta-analysis of the results by gender and $95 \%$ CI were applied to the two articles $[21,28]$ that presented RR by male/female. The resulting forest plot is shown in Figure 3. The sRR value applied to the fixed effects model at $25.9 \%$ of the I-squared [18] value was 0.99 (95\% 


\begin{tabular}{|c|c|c|}
\hline $\begin{array}{l}\text { Study } \\
\text { ID }\end{array}$ & $\begin{array}{l}\text { Relative risk } \\
(95 \% \mathrm{Cl})\end{array}$ & $\begin{array}{c}\% \\
\text { Weight }\end{array}$ \\
\hline 21 & $0.95(0.62,1.45)$ & 1.89 \\
\hline 22 & $1.12(0.68,1.84)$ & 1.40 \\
\hline 23 & $1.08(0.82,1.43)$ & 4.43 \\
\hline 24 & $1.05(0.74,1.49)$ & 2.80 \\
\hline 25 & $1.12(0.86,1.45)$ & 5.02 \\
\hline 26 & $0.99(0.93,1.06)$ & 79.90 \\
\hline 27 & $0.79(0.57,1.10)$ & 3.17 \\
\hline 28 & $0.53(0.33,0.87)$ & 1.41 \\
\hline Overall (I-squared $=25.9 \%, p=0.223$ ) & $0.99(0.93,1.05)$ & 100.00 \\
\hline 0.1 & $\begin{array}{l}T \\
10\end{array}$ & \\
\hline
\end{tabular}

Figure 3. A forest plot using fixed-effects summary estimates in 8 cohort articles evaluating the association between intake of citrus fruits and pancreatic cancer risk. ID, reference number; $\mathrm{Cl}$, confidence interval.

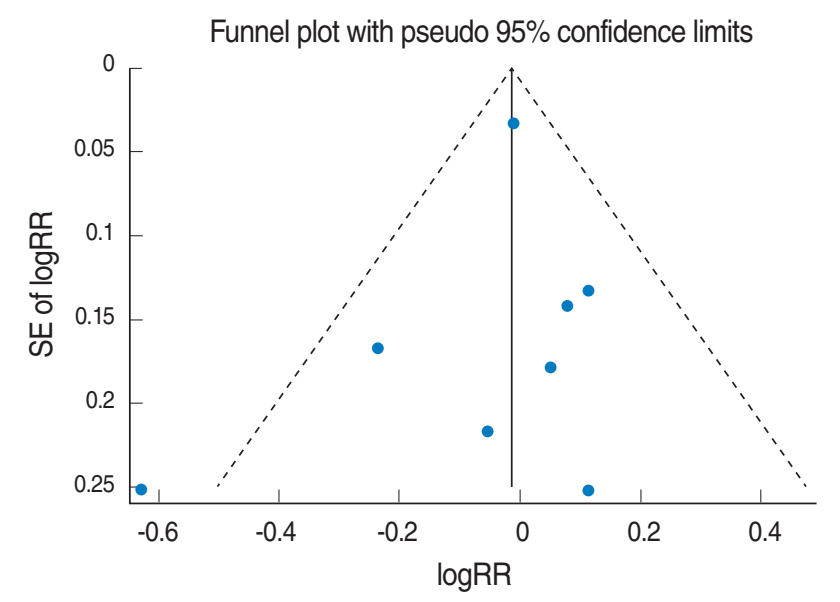

Figure 4. A funnel plot using fixed-effects summary estimates in 8 cohort articles evaluating the association between intake of citrus fruits and pancreatic cancer risk. logRR, log relative risk; SE of $\log R R$, standard error of log relative risk.

CI, 0.93 to 1.05), indicating it was not statistically significant. Begg's test resulted in a p-value of 0.45 , indicating no effect for the small-scale study, and there was no asymmetry effect on the corresponding funnel plot (Figure 4).

\section{DISCUSSION}

According to the SR results in the COSs, there were no statistically significant results in allergic history and citrus fruit intake, respectively. When subgroup analysis results were contradictory between CCS and COS, it is reasonable to accept the SR result of the COS, rather than the CCS, due to the level of evidence [30].

However, when an analytical epidemiology study to reveal causality is performed on rare diseases with a low incidence like pancreatic cancer, a CCS study design is recommended, because COS needs a large group of participants. On the contrary, since CCS has a problem with recall bias risk on history of exposure [31], a pooled analysis study was recently performed with a larger number of research participants. In other words, after the meta-analysis report on citrus fruit [7], there was no statistically significant result found in a pooled analysis with 14 cohorts [26], while some experimental studies on citrus fruit components were published [4]. After the meta-analysis report on allergic history in 2005 [6], a pooled analysis that was performed with 10 CCSs resulted in a reduction of incidence risk [32]. However, there has been no report of pooled analysis with cohorts.

Of course, there is still a chance that measurement error in the history of exposure will persist, even in COS. For example, 
epidemiologic studies mostly depend on self-reported responses for allergic history and diet intake levels [26,31]. Furthermore, methodological limitations, such as a short of follow-up period and follow-up loss make it difficult to reveal causality [33]. In addition, since exposure levels applied to meta-analysis are relative levels, depending on distribution of intake amount it is hard to secure consistency between cohorts in the exposure level.

For now, SR of CCS results have consistently reported a reduced cancer risk, so that expert reviews have suggested that citrus fruit intake [4] and allergic history [31,32] had inhibitory effects on pancreatic cancer incidence. Therefore, it is necessary to investigate the hypothesis concerning the interactional effect of allergic history and citrus fruit intake, considering the pancreatic cancer incidence rate in Jeju Island. To date, there has been no analytical epidemiological study on the interaction between allergic history and citrus fruit intake in their inhibitory effects on pancreatic cancer, either inside or outside of Korea. Thus, I propose to perform an epidemiologic study on these interactional effect with cohorts securing both explanatory variables.

\section{ACKNOWLEDGMENTS}

The present study was funded by a research promotion grant from Jeju National University in 2015.

\section{CONFLICT OF INTEREST}

The author has no conflicts of interest to declare for this study.

\section{SUPPLEMENTARY MATERIAL}

Supplementary material is available at http://www.e-epih.org/.

\section{REFERENCES}

1. Siegel R, Naishadham D, Jemal A. Cancer statistics, 2012. CA Cancer J Clin 2012;62:10-29.

2. Klapman J, Malafa MP. Early detection of pancreatic cancer: why, who, and how to screen. Cancer Control 2008;15:280-287.

3. Jung KW, Won YJ, Kong HJ, Oh CM, Lee DH, Lee JS. Cancer statistics in Korea: incidence, mortality, survival, and prevalence in 2011. Cancer Res Treat 2014;46:109-123.

4. Pericleous M, Rossi RE, Mandair D, Whyand T, Caplin ME. Nutrition and pancreatic cancer. Anticancer Res 2014;34:9-21.

5. Lowenfels AB, Maisonneuve P. Epidemiology and risk factors for pancreatic cancer. Best Pract Res Clin Gastroenterol 2006;20:197-
209.

6. Gandini S, Lowenfels AB, Jaffee EM, Armstrong TD, Maisonneuve P. Allergies and the risk of pancreatic cancer: a meta-analysis with review of epidemiology and biological mechanisms. Cancer Epidemiol Biomarkers Prev 2005;14:1908-1916.

7. Bae JM, Lee EJ, Guyatt G. Citrus fruit intake and pancreatic cancer risk: a quantitative systematic review. Pancreas 2009;38:168-174.

8. Bae JM. Explaining cancer incidence in the Jejudo population. J Prev Med Public Health 2009;42:67-72 (Korean).

9. Bae JM, Shin KS. Estimating the prevalence of atopic dermatitis in school students of Jejudo, Korea. J Prev Med Public Health 2009;42: 171-176 (Korean).

10. McWhorter WP. Allergy and risk of cancer. A prospective study using NHANESI followup data. Cancer 1988;62:451-455.

11. Mills PK, Beeson WL, Abbey DE, Fraser GE, Phillips RL. Dietary habits and past medical history as related to fatal pancreas cancer risk among Adventists. Cancer 1988;61:2578-2585.

12. Eriksson NE, Holmén A, Högstedt B, Mikoczy Z, Hagmar L. A prospective study of cancer incidence in a cohort examined for allergy. Allergy 1995;50:718-722.

13. Stolzenberg-Solomon RZ, Pietinen P, Taylor PR, Virtamo J, Albanes D. A prospective study of medical conditions, anthropometry, physical activity, and pancreatic cancer in male smokers (Finland). Cancer Causes Control 2002;13:417-426.

14. Bae JM. Narrative reviews. Epidemiol Health 2014;36:e2014018.

15. Bae JM. Human papillomavirus 16 infection as a potential risk factor for prostate cancer: an adaptive meta-analysis. Epidemiol Health 2015; 37:e2015005.

16. Eriksson NE, Mikoczy Z, Hagmar L. Cancer incidence in 13811 patients skin tested for allergy. J Investig Allergol Clin Immunol 2005; 15:161-166.

17. Hagströmer L, Ye W, Nyrén O, Emtestam L. Incidence of cancer among patients with atopic dermatitis. Arch Dermatol 2005;141:1123-1127.

18. Higgins JP, Thompson SG. Quantifying heterogeneity in a meta-analysis. Stat Med 2002;21:1539-1558.

19. Coughlin SS, Calle EE, Patel AV, Thun MJ. Predictors of pancreatic cancer mortality among a large cohort of United States adults. Cancer Causes Control 2000;11:915-923.

20. Stolzenberg-Solomon RZ, Pietinen P, Taylor PR, Virtamo J, Albanes D. Prospective study of diet and pancreatic cancer in male smokers. Am J Epidemiol 2002;155:783-792.

21. Lin Y, Kikuchi S, Tamakoshi A, Yagyu K, Obata Y, Inaba Y, et al. Dietary habits and pancreatic cancer risk in a cohort of middle-aged and elderly Japanese. Nutr Cancer 2006;56:40-49.

22. Larsson SC, Håkansson N, Näslund I, Bergkvist L, Wolk A. Fruit and vegetable consumption in relation to pancreatic cancer risk: a prospective study. Cancer Epidemiol Biomarkers Prev 2006;15:301-305.

23. Nöthlings U, Murphy SP, Wilkens LR, Henderson BE, Kolonel LN. Dietary glycemic load, added sugars, and carbohydrates as risk factors for pancreatic cancer: the Multiethnic Cohort Study. Am J Clin Nutr 2007;86:1495-1501.

24. Bobe G, Weinstein SJ, Albanes D, Hirvonen T, Ashby J, Taylor PR, et al. Flavonoid intake and risk of pancreatic cancer in male smokers (Finland). Cancer Epidemiol Biomarkers Prev 2008;17:553-562.

25. Vrieling A1, Verhage BA, van Duijnhoven FJ, Jenab M, Overvad K, Tjønneland A, et al. Fruit and vegetable consumption and pancreatic cancer risk in the European Prospective Investigation into Cancer and Nutrition. Int J Cancer 2009;124:1926-1934.

26. Koushik A, Spiegelman D, Albanes D, Anderson KE, Bernstein L, van den Brandt PA, et al. Intake of fruits and vegetables and risk of pancreatic cancer in a pooled analysis of 14 cohort studies. Am J Ep- 
idemiol 2012;176;373-386.

27. Heinen MM, Verhage BA, Goldbohm RA, van den Brandt PA. Intake of vegetables, fruits, carotenoids and vitamins $\mathrm{C}$ and $\mathrm{E}$ and pancreatic cancer risk in The Netherlands Cohort Study. Int J Cancer 2012; 130:147-158.

28. Shigihara M, Obara T, Nagai M, Sugawara Y, Watanabe T, Kakizaki $\mathrm{M}$, et al. Consumption of fruits, vegetables, and seaweeds (sea vegetables) and pancreatic cancer risk: the Ohsaki Cohort Study. Cancer Epidemiol 2014;38:129-136.

29. Li WQ, Kuriyama S, Li Q, Nagai M, Hozawa A, Nishino Y, et al. Citrus consumption and cancer incidence: the Ohsaki cohort study. Int J Cancer 2010;127:1913-1922.

30. Duke University Medical Center Library; Health Sciences Library at the University of North Carolina at Chapel Hill. Type of questions and studies [cited 2015 Apr 13]. Available from: http://www.hsl.unc. edu/Services/Tutorials/EBM/Supplements/QuestionSupplement.htm.

31. Turner MC, Chen Y, Krewski D, Ghadirian P. An overview of the association between allergy and cancer. Int J Cancer 2006;118:31243132.

32. Rittmeyer D, Lorentz A. Relationship between allergy and cancer: an overview. Int Arch Allergy Immunol 2012;159:216-225.

33. Olson SH, Hsu M, Satagopan JM, Maisonneuve P, Silverman DT, Lucenteforte E, et al. Allergies and risk of pancreatic cancer: a pooled analysis from the Pancreatic Cancer Case-Control Consortium. Am J Epidemiol 2013;178:691-700. 